\title{
DESIGN MODIFICATIONS FOR INCREASING THE BOM AND EOM POWER OUTPUT AND REDUCING THE SIZE AND MASS OF RTG FOR THE PLUTO MISSION
}

\author{
Alfred Schock, Chuen Tak Or, and Vasanth Kumar \\ Fairchild Space and Defense Corporation \\ Germantown, MD 20874
}

\begin{abstract}
A companion paper analyzed the effect on RTG power output of varying the number of heat source modules for three specific fuel options, and compared the predicted power output with JPL's latest goals for the Pluto Fast Flyby (PFF) mission. The results showed that a 5-module RTG cannot fully meet JPL's goals with any of the available fuels; and that a 6-module RTG more than meets those goals with Russian fuel, almost meets them with US. (Cassini-type) fuel, but still falls far short of meeting them with the depleted fuel from the aged (1982) Galileo spare RTG. The inadequacy of the aged fuel was disappointing, because heat source modules made from it already exist, and their use in PFF could result in substantial cost savings. The present paper describes additional analyses which showed that a six-module RTG with the aged fuel can meet JPL's stipulated power margin with a relatively simple design modification, that a second design modification makes it possible to recover all of the mass and size penalty for going from five to six heat source modules, and that a third modification could raise the EOM power margin to $16 \%$.
\end{abstract}

\section{INTRODUCTION}

Figure 1 depicts cross-sectional views of the previously analyzed RTG containing six General Purpose Heat Source (GPHS) modules and 192 unicouples. These were described in detail in the preceding paper ${ }^{1}$. As seen, the 192 unicouples are arranged in 12 rings of 16 , two rings per heat source module. This arrangement is identical to that use in the 18-module RTGs successfully flown on the Galileo and Ulysses mission. ${ }^{2}$

The predicted power profile of the above RTG during the 8.2-year PFF mission is depicted in Figure 2 for three specific fuel options, with respective BOM thermal powers of 254,234 , and 220 watts per heat source modulc. For each fuel option, the figure shows the BOM efficiency, the optimum RTV voltage, and the BOM and EOM hot-
Figure 1. Cross-Sectional View of Baseline RTG

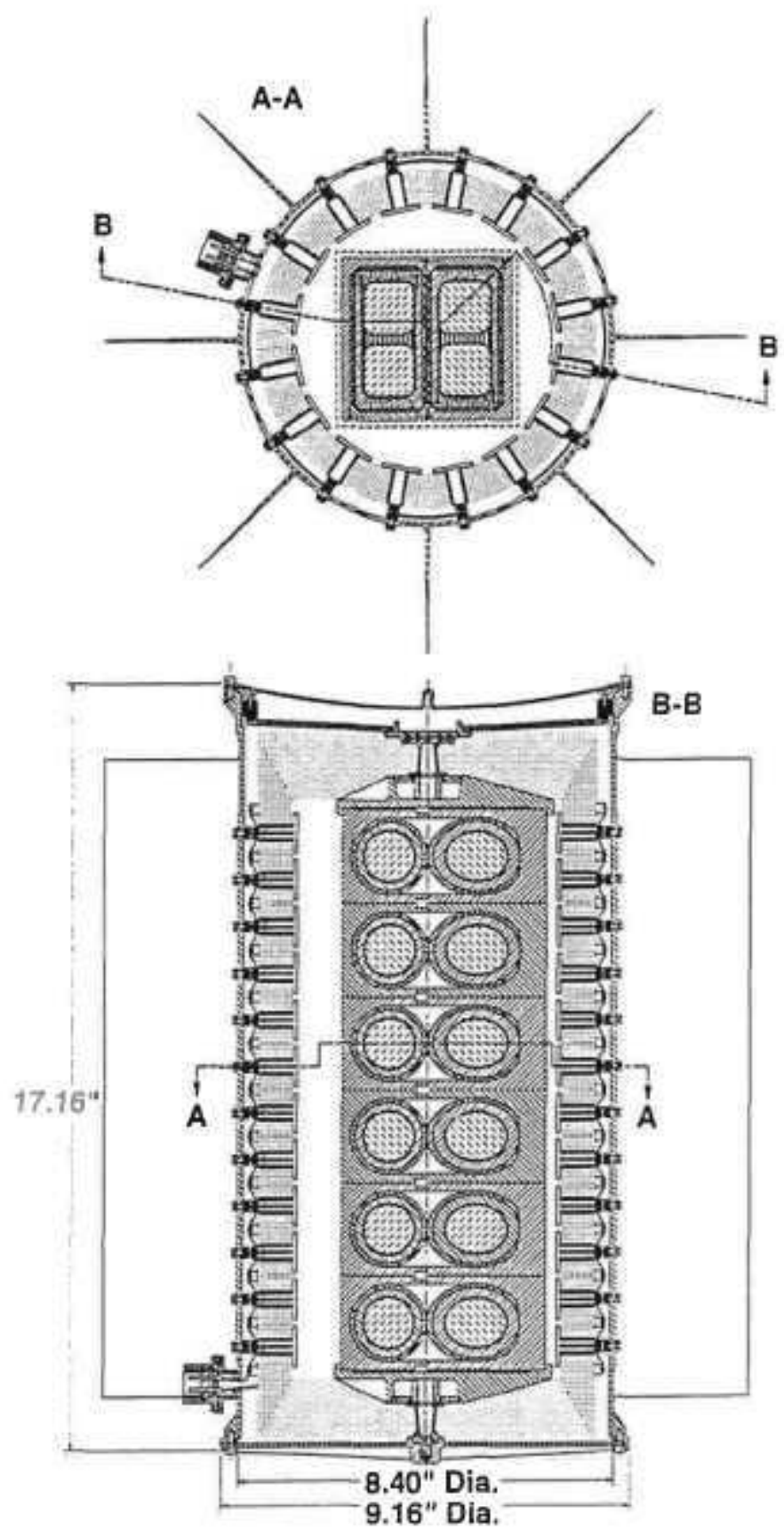


junction temperatures. It also shows the key PFF power demand goals stipulated by JPL, including $20 \%$ contingencies plus $10 \%$ margin. As can be seen, those power goals are easily met with the high-enrichment Russian fuel, almost met with the U.S. (Cassini-type) fuel, and not at all met with the aged fuel contained in the left-over Galileo spare (F5) RTG.

Figure 2. Effect of Fuel Option on RTG Power Profile versus PFF Demand

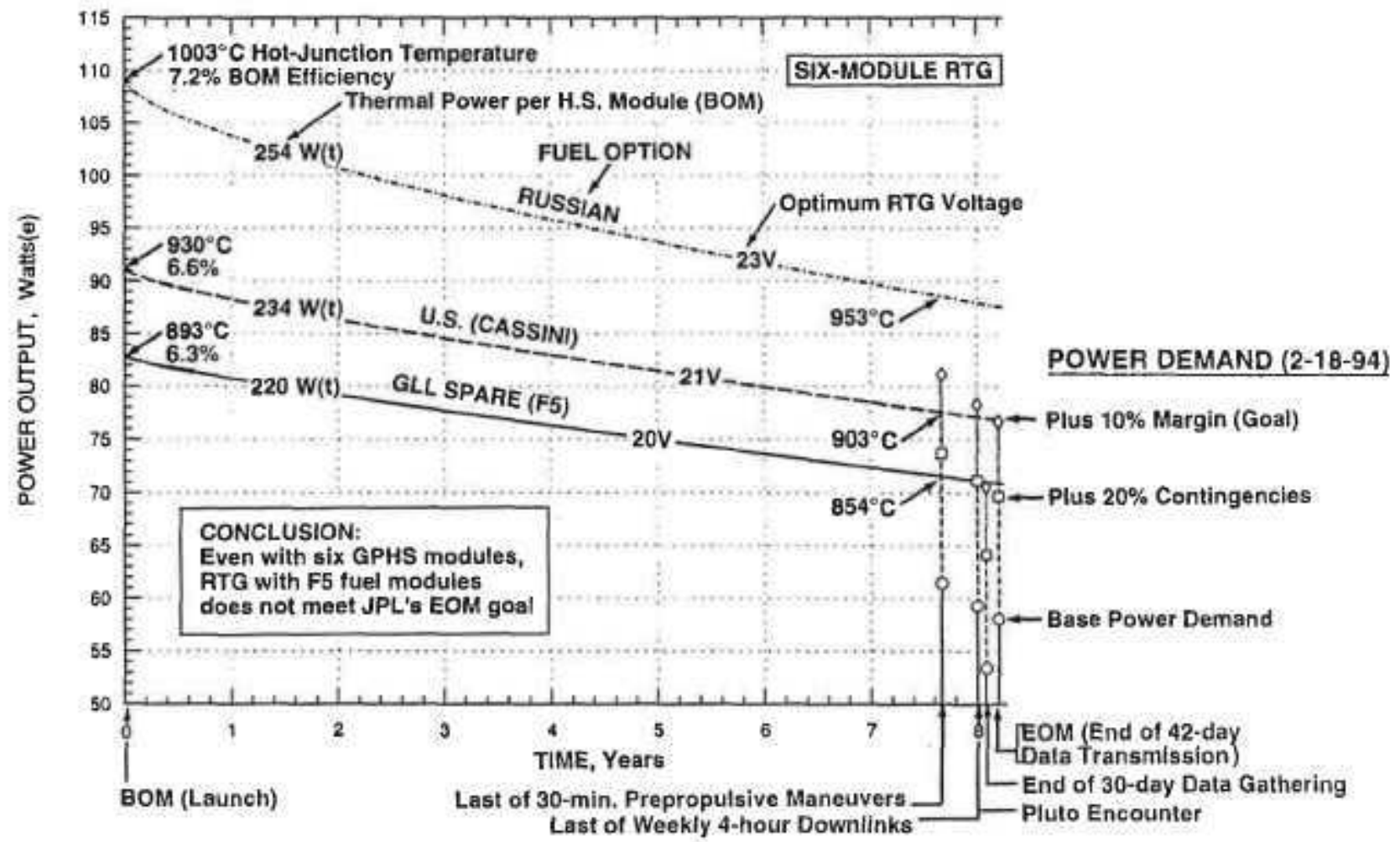

The failure of the aged fuel to meet the PFF power demand goal was disappointing, because a sufficient number of heat source modules with that fuel already exist, and their use could result in significant cost savings for the severely costconstrained PFF mission. Therefore, Fairchild undertook a study to determine whether the RTG design could be modified (without increasing its mass) to meet the mission's EOM power demand goal.

\section{FIRST DESIGN MODIFICATION}

A simple solution for increasing the RTG's power output is suggested by comparison of the upper and lower curves of Figure 2. It is clear that the RTG with Galileo spare fuel yields a lower electrical output not only because its thermal power is lower but also because its efficiency is significantly lower. Its efficiency is lower because its hot-junction temperature is much lower, because of the depleted fuel's reduced thermal power.

Nothing can be done about the depleted fuel's lower thermal power, but something can be done about the RTG's lower hot-junction temperature. Note that the high-enrichment Russian fuel yields a BOM hot-junction temperature of $1003^{\circ} \mathrm{C}$, which is about the limit of experience on previous flight RTGs. (Accelerated life tests have been conducted at higher temperatures.) As shown, the same RTG with depleted fuel has a BOM hotjunction temperature of only $893^{\circ} \mathrm{C}$, which accounts for its much lower efficiency ( $6.3 \%$ versus $7.2 \%$ ).

Clearly, the way to raise the RTG's efficiency is to raise its hot-junction temperatures. Can this be done without increasing the thermal power? Yes, by reducing the thermal conductance of the thermopile.

One way of reducing the thermopile's conductance is to lower the conductance of each thermoelectric leg, by increasing its length and/or reducing its cross-sectional area. But that would require revising the unicouple design and repeating lengthy qualification tests, clearly a very undesirable strategy considering how much effort has gone into perfecting the fabrication of the present unicouples and demonstrating their longevity. A much better strategy is to leave the unicouple design unchanged, but reduce the number of unicouples in the RTG. 
This strategy is illustrated in Figure 3, which compares the standard six-module RTG with one in which the number of unicouple rings has been reduced from 12 to 10 . As shown at the bottom of the figure, this raises the BOM hot-junction temperature from $893^{\circ} \mathrm{C}$ to $994^{\circ} \mathrm{C}$ (still within the established $1000^{\circ} \mathrm{C}$ limit), and raises the BOM efficiency from $6.3 \%$ to $7.2 \%$.

In Figure 3, the reduced number of couple rings have been spread out over the full length of the heat source stack. This only requires the relatively trivial change of lengthening the axial series connectors between adjacent couple rings. Alternatively, we have analyzed two cases in which the spacing between couple rings is kept the same, by deleting the couple ring at each end or by omitting two couple rings at the center of the RTG. All three alternatives surprisingly gave essentially identical results.

Figure 4 shows the effect of varying the number of couple rings on the RTG's power profile during the 8.2year mission, and compares those profiles with JPL's stipulated demand goals. As can be seen, RTGs with 12 and 11 coupled rings do not provide the stipulated $10 \%$ margin, but the 10-ring RTG meets that goal after encounter and only misses it by $\sim 3 \%$ during the final prepropulsive maneuvers.

The figure shows that deleting two couple rings raises the BOM output by $14 \%$ and the EOM output by $10 \%$. The reason for the smaller improvement at EOM is that part of the BOM gain is subsequently lost due to greater degradation rates at the higher hot-junction temperatures.

It may be wondered, if this is so effective why stop at 10 rings? Why not go to nine and achieve even greater improvement? We did analyze a 9-ring design, but found it to be self-defeating. Going to nine rings led to a large increase in $\mathrm{BOM}$ power, but the consequent rise in hot-junction
Figure 3. Effect of Reduced Number of Standard Unicouples on PFF RTG with 6 GPHS Modules from GLL Spare (F5)

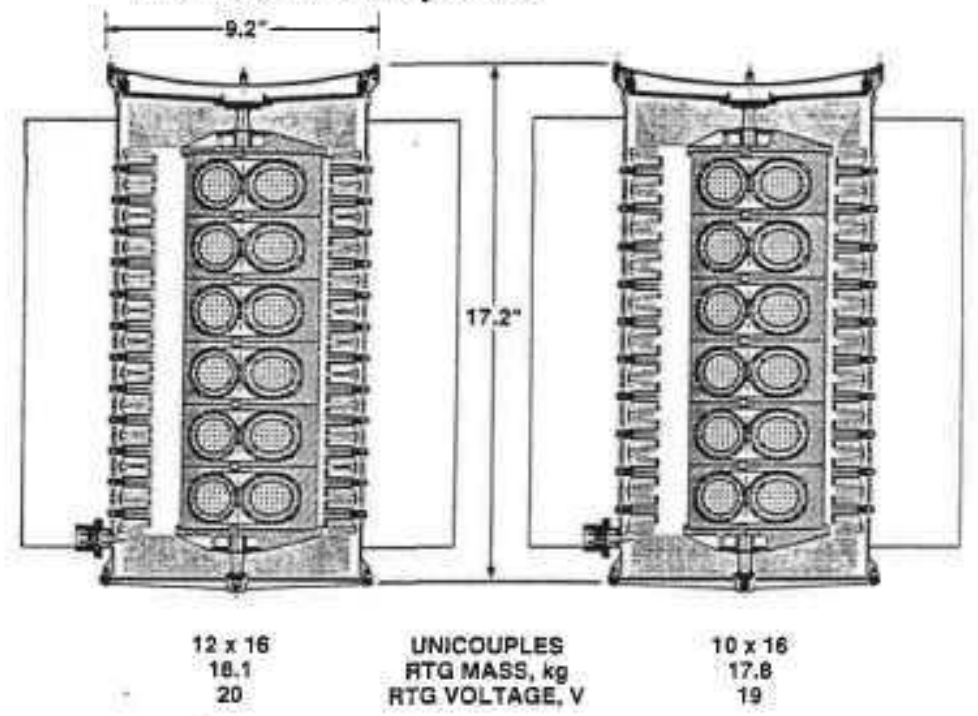

\begin{tabular}{|c|c|c|c|c|}
\hline$\underset{0}{\mathrm{BOM}}$ & $\begin{array}{l}\text { EOM } \\
\text { B.2 }\end{array}$ & $\begin{array}{l}\text { ATG PEAFOAMANCE } \\
\text { YEAAS FAOU LAUNEW }\end{array}$ & $\underset{0}{\operatorname{agn}}$ & $\underset{82.2}{\text { EOM }}$ \\
\hline $\begin{array}{l}1320 \\
893 \\
240\end{array}$ & $\begin{array}{l}1237 \\
854 \\
231\end{array}$ & $\begin{array}{l}\text { THERMAL POWER, W(t) } \\
\text { HOT-JUNCTION, 'C } \\
\text { COLD-JUNCTION, "C }\end{array}$ & $\begin{array}{l}1320 \\
994 \\
230\end{array}$ & $\begin{array}{l}1237 \\
953 \\
230\end{array}$ \\
\hline $\begin{array}{l}6.3 \\
83\end{array}$ & 5.7 & $\begin{array}{l}\text { ATG EFFICIENCY, } \% \\
\text { OUTPUT POWER, W(e) }\end{array}$ & $\begin{array}{l}7.2 \\
95\end{array}$ & $\begin{array}{l}6.3 \\
78\end{array}$ \\
\hline
\end{tabular}

Figure 4. Effect of Number of 16-Unicouple Rings on PFF RTG with 6 GLL-Spare GPHS Modules Thermal Power $=1320 \mathrm{~W}$ at Launch, $1237 \mathrm{~W}$ at Flyby. Opt Voltage $=19 \mathrm{~V}$

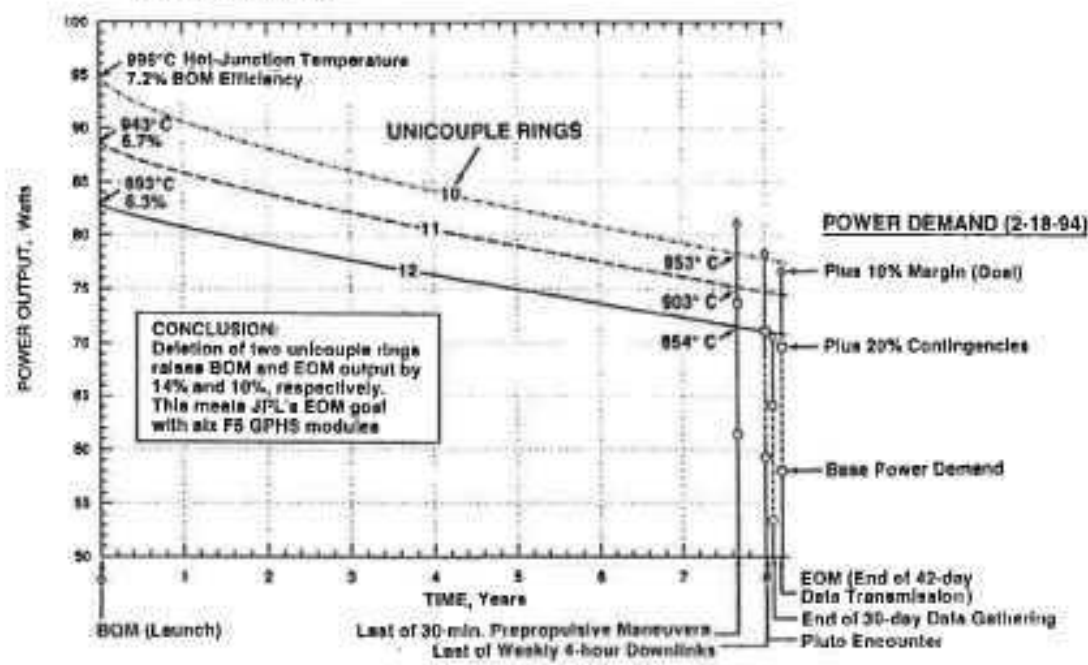

temperature and degradation rate actually resulted in a lower EOM power than the ten-ring RTG. Therefore, for a six-module RTG with the depleted fuel, the design with ten unicouple rings appears to be optimum and will be assumed in the balance of this report. 


\section{SECOND DESIGN MODIFICATION}

Independent of the above-described modification, we generated a second modification to reduce the RTG's size and mass. This second modification relates primarily to the method of compressivly supporting the stack of heat source modules. The support system must be robust enough to hold the heat source stack together under the anticipated launch loads, while minimizing the heat losses through the support elements which penetrate the multifoil thermal insulation. In the case of the 18-module RTGs used for the previously launched Galileo and Ulysses missions and the upcoming Cassini mission, heat source support is provided by four titanium studs in series with zirconia bushings at each end of the heat source stack.

Since, the difficulty of supporting a heat source stack is proportional to the square of its length. Supporting a six-module stack is nine times casier than supporting an 18-module stack. Therefore, the author previously recommended ${ }^{3}$ using a single stud and bushing at each end of the PFF RTG, as illustrated in Figure 1. Subsequent analysis indicated that this would survive launch, but that conclusion would have to be verified by further analyses and qualification tests.

The design modification proposed here is to replace the titanium stud and zirconia bushing at each end of the PFF RTG with four much smaller pyrolytic-graphite (PG) studs. As shown in Figure 5, each corner of the heat source stack is supported by a PG button. Pyrolytic graphite is a good thermal insulator in the direction normal to its deposition planes. It has good compressive strength, but very poor shear strength. As shown, the eight PG studs all point at the center of the heat source. Thus, shear loads are minimized, and the heat source is supported in every direction by compressive loads on the PG studs.

A major feature of the revised concept illustrated in Figure 6 is that final adjustments of the load studs can be made from outside the housing of the generator, after it has been assembled and its temperatures have equilibrated. This makes it possible to compensate for tolerances, thermal expansion effects, and creep effects during long-term storage before launch. Clearly, structural analyses and vibration tests would be required to qualify this support scheme for launch, but that is also true of the support scheme it replaces.
Figure 5. Heat Source Support Scheme for Revised RTG Design

Adjustable from Outside the RTG Housing Requires Qualification Test with Dummy Modules

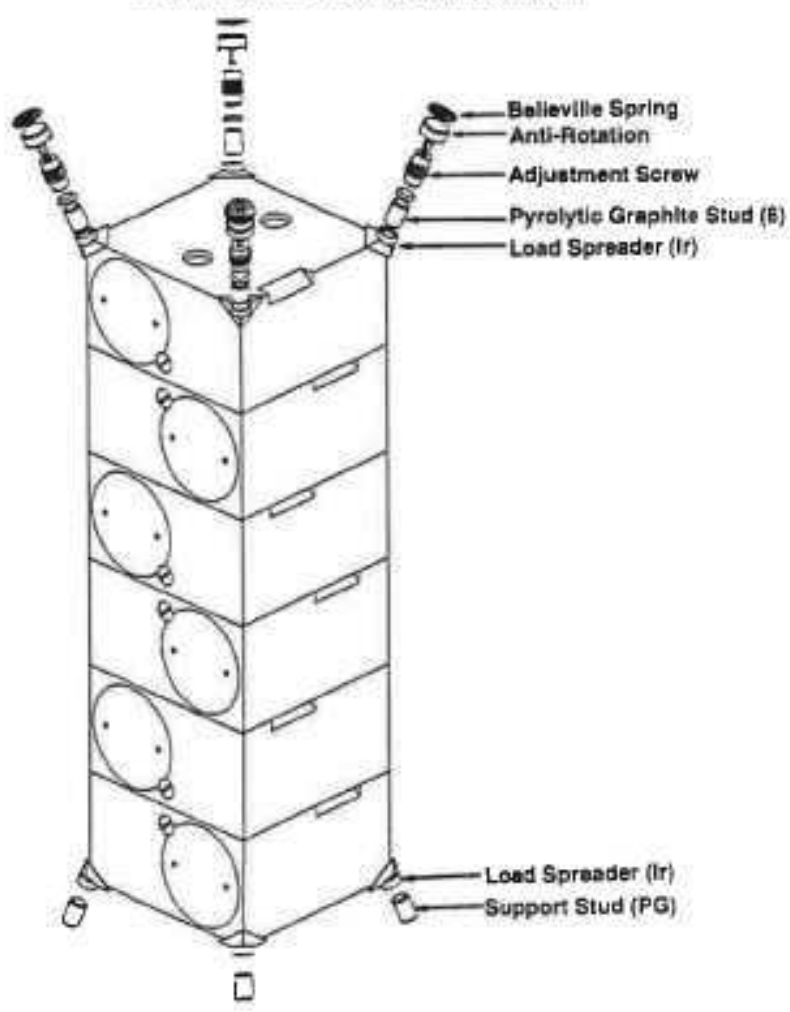

Figure 6. Cutaway View of Revised RTG Design

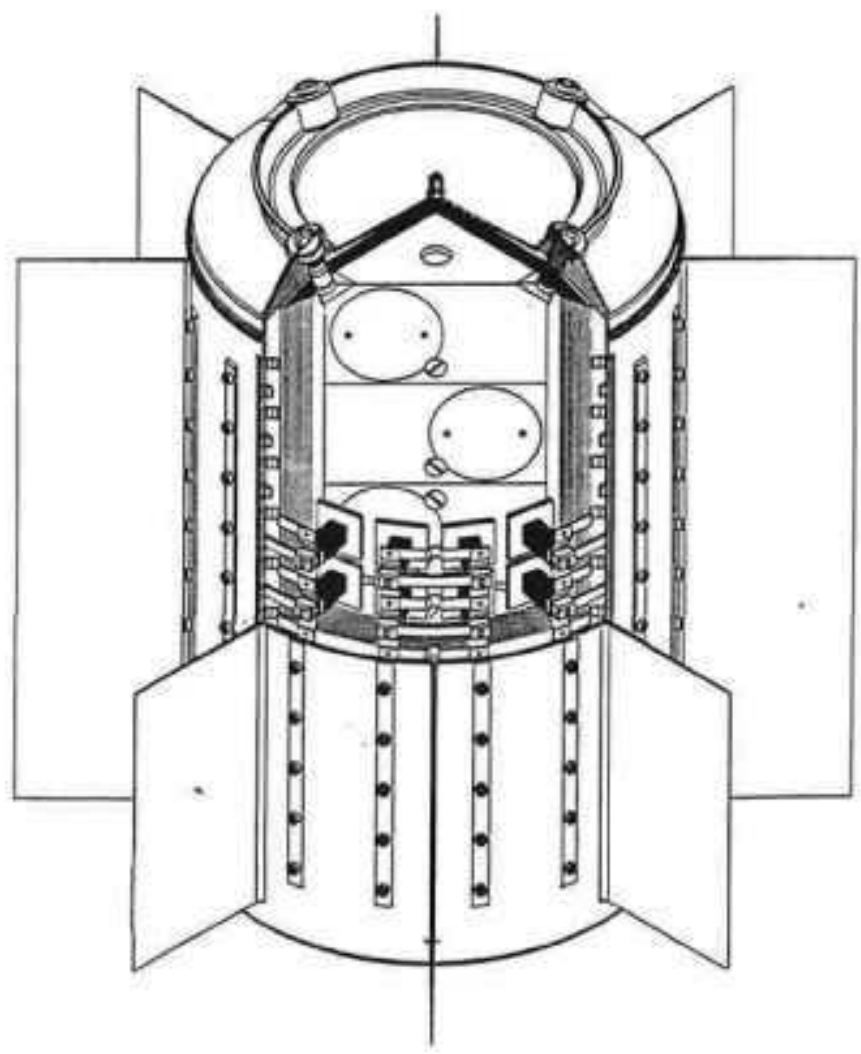


Figure 7 compares the revised design with the previous (baseline) design. As can be seen, the design revisions reduce the RTG's height by $2.6^{\text {" }}$ and its mass by $2.4 \mathrm{~kg}$. These reductions more than balance the previous penalties in going from five to six heat source modules.

\section{THIRD DESIGN MODIFICATION}

This is not really a design modification but rather a modification in operating procedure. Traditionally, RTGs have operated at constant voltage to maximize their power output. Their constant output voltage regardless of fuel decay and varying load demand has been maintained by a shunt regulator. When the RTG's power output exceeds the demand, which is most of the time, the excess power is dissipated by the shunt regulator and radiated to space. This was also the assumption in the analyses described thus far.

The author decided to explore whether the need for a shunt regulator and its radiator can be eliminated by matching the RTG's power output to the power demand at all times, by operating it at less than optimum voltage when full power is not needed; and to determine whether this reduced-voltage operation would significantly reduce the power degradation rate by increasing the RTG's output current and its Peltier cooling rate, which lowers the hot-junction temperature and the thermoelectric degradation rate. The above principles are illustrated in Figures 8, 9, and 10.

Figure 8 shows how - for any given thermal power - the RTG's output can be reduced from its maximum value by deviating from its optimum voltage. Power output can be reduced by operating either above or below the optimum voltage, but clearly it is preferable to operate below the optimum voltage to increase the current and the Peltier cooling rate. The resultant effect on hot-junction temperature is shown in Figure 9.
Figure 7. Comparison of Previous and Revised PFF RTGs 6 Depleted (F-5) Heat Source Modules, 10 Standard Unicouple Bings

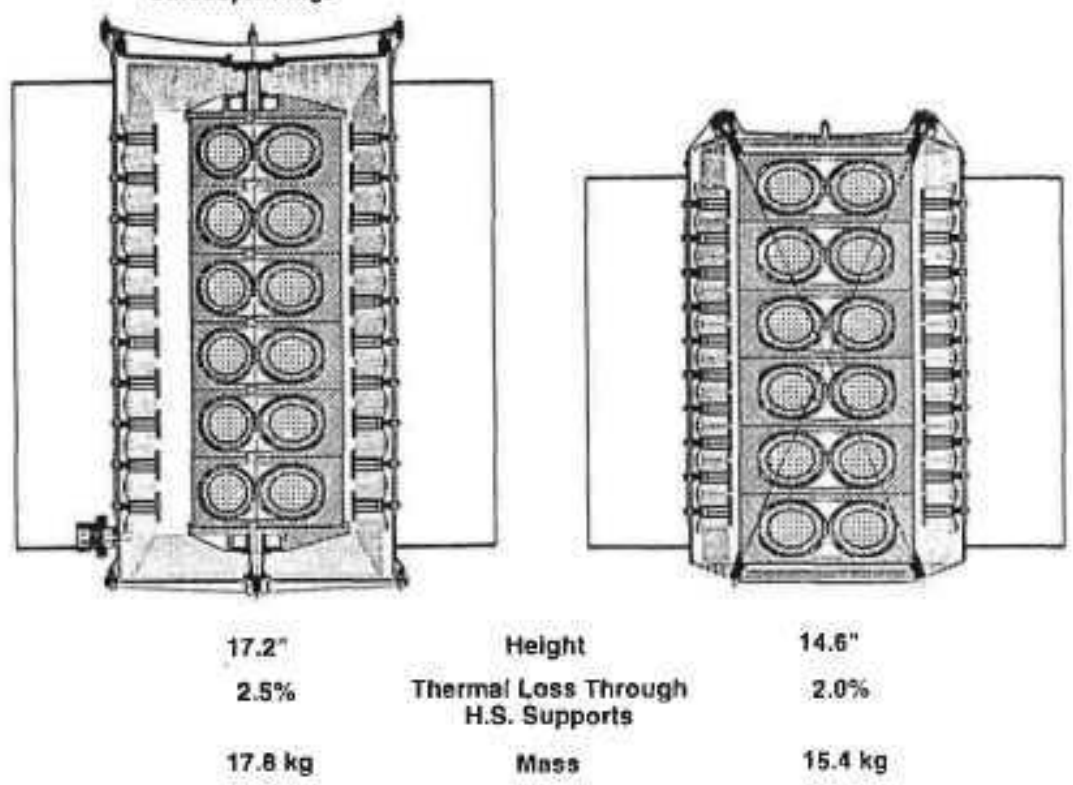

Figure 8. Effect of RTG* Voltage and Thermal Power on Electrical Output

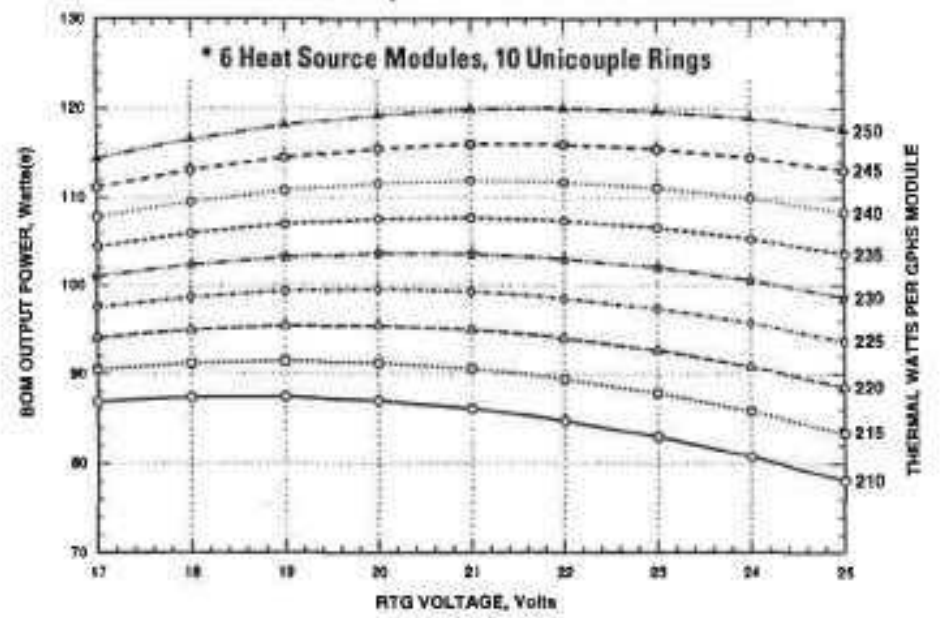

Figure 9. Effect of RTG* Voltage and Thermal Power on Hot-Junction Temperature

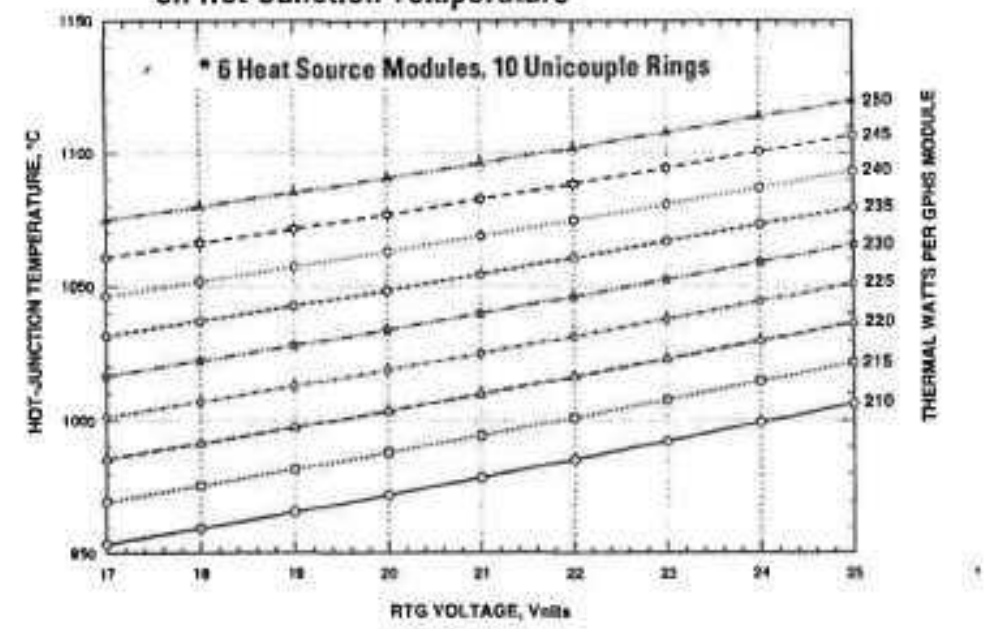


Figure 10 displays a cross-plot of hot-junction temperature versus output power, with voltage as the implicit variable. Clearly, when maximum power is not needed, operating at less than optimum voltage can significantly reduce the hotjunction temperature and therefore the thermoelectric degradation rate.

Before applying the above variablevoltage approach to the PFF mission, let us first review JPL's latest power demand schedule. That schedule is summarized in Table 1. As seen, the mission consists of an 8-year preencounter phase with a weekly 4-hour downlink period and several 30 -minute prepropulsive and propulsive maneuvers, a 30-day encounter phase with daily 16 hours of data gathering and 8 hours of data transmission, followed by a 6 -week post-encounter cruise with full-time data transmission. For each activity, the table lists the breakdown of the power demand and the total demand with a $20 \%$ contingency allowance plus a $10 \%$ margin, which is JPL's stipulated power goal. As will be seen, the most critical demands are the last of the prepropulsive maneuvers, the last of the weekly downlinks before encounter, and the data transmissions after encounter.

Possible application of the variablevoltage scheme to the PFF mission is illustrated in Figures 11 through 14. Each figure compares mission profiles for the variable-voltage option (solid lines) with those for the conventional fixed-voltage option (dashed lines).

Figure 11 shows the variation of RTG voltage with time. Note that RTG operation during most of the long cruise period is at a very low voltage ( 8 to 9 volts). Only during the weekly 4 hour downlinks is the voltage raised (to 11-15 volts). Shortly before and after encounter, when power demand is at a maximum, the RTG operates at $18 \mathrm{~V}$.
Figure 10. Hot-Junction Temperature Versus RTG* Power for Various Thermal Powers - 6 Heat Source Modules, 10 Unicouple Rings

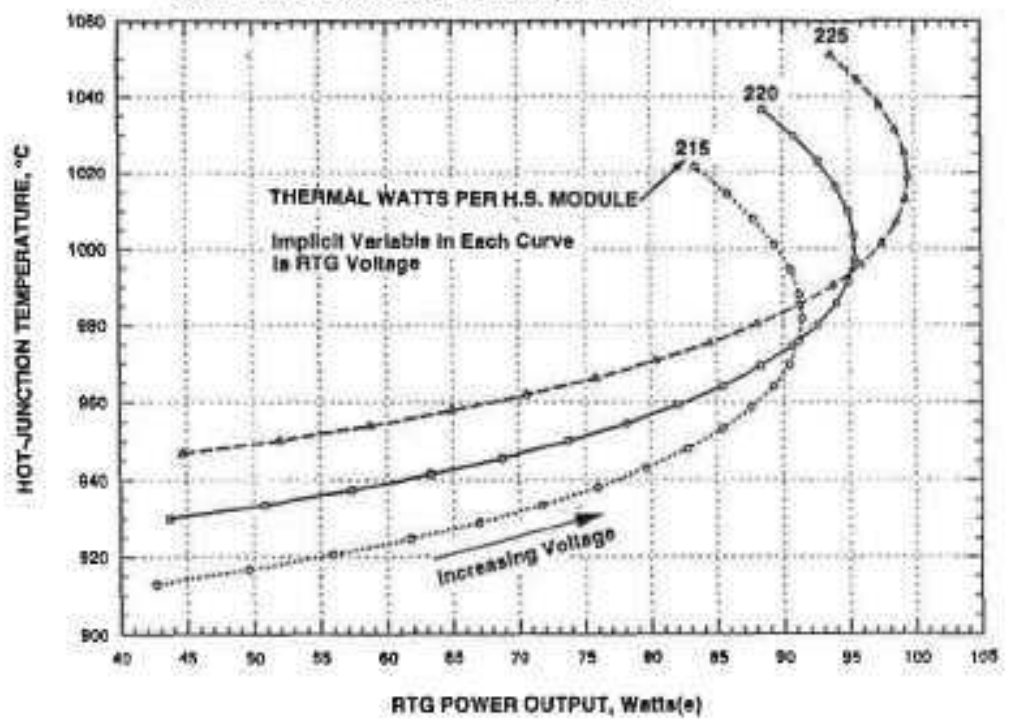

Table 1. JPL's Baseline Power Demand Schedule for PFF (2-18-94)

\begin{tabular}{|c|c|c|c|c|c|c|}
\hline \multirow{2}{*}{$\begin{array}{l}\text { Misalon Phase } \\
\text { Duration } \\
\text { Modie " } \\
\text { Activilay Time }\end{array}$} & \multicolumn{3}{|c|}{$\begin{array}{c}\text { Pre. Encounter } \\
\text { E years }\end{array}$} & \multicolumn{2}{|c|}{$\begin{array}{l}\text { Encounter } \\
30 \text { days }\end{array}$} & \multirow{2}{*}{$\begin{array}{c}\begin{array}{c}\text { Posi- } \\
\text { Encounter } \\
6 \text { weaks }\end{array} \\
7 \\
24 \text { hriday }\end{array}$} \\
\hline & $\frac{1}{164 \mathrm{hrimk}}$ & $\begin{array}{c}2 \\
\text { intiwk }\end{array}$ & $\begin{array}{c}3 \\
20 \times 30 \mathrm{~min}\end{array}$ & $\begin{array}{c}6 \\
18 \text { hriday }\end{array}$ & $\begin{array}{c}6 \\
\text { e hridaly }\end{array}$ & \\
\hline Actlvity & Crulse & Downilnk & \begin{tabular}{|c|} 
Pre: \\
Propulative \\
Maneuvers \\
\end{tabular} & $\begin{array}{c}\text { Doto } \\
\text { Gathering }\end{array}$ & \multicolumn{2}{|c|}{$\begin{array}{c}\text { Data } \\
\text { Trensmission }\end{array}$} \\
\hline $\begin{array}{l}\text { Power (Watts) } \\
\text { Telecommunicalion } \\
\text { Power Conditioning } \\
\text { Altitude Control } \\
\text { Data Proeessing } \\
\text { Propulslon } \\
\text { Thermal Control } \\
\text { Sclence. }\end{array}$ & $\begin{array}{l}9.0 \\
12.2 \\
9.7 \\
13.6 \\
0.4 \\
1.0 \\
1.0\end{array}$ & $\begin{array}{l}24,0 \\
14,7 \\
9.7 \\
8.6 \\
18,9 \\
1.0 \\
1.0\end{array}$ & $\begin{array}{c}9.0 \\
15.1 \\
9.0 \\
8.6 \\
16.8 \\
1.0 \\
1.0\end{array}$ & $\begin{array}{l}9.0 \\
13.6 \\
18.0 \\
6.6 \\
0.4 \\
1.0 \\
6.0\end{array}$ & \multicolumn{2}{|c|}{$\begin{array}{l}24.0 \\
14.4 \\
9.7 \\
13.6 \\
0.4 \\
1.0 \\
0.0\end{array}$} \\
\hline $\begin{array}{l}\text { Total Power Demand } \\
\text { IncL. } 20 \% \text { cootingency } \\
\text { incl. } 10 \% \text { margin }\end{array}$ & $\begin{array}{l}46.8 \\
58.2 \\
51.8\end{array}$ & $\begin{array}{l}50.3 \\
71.2 \\
8.3\end{array}$ & $\begin{array}{l}61.4 \\
73.7 \\
81.1\end{array}$ & $\begin{array}{l}53.4 \\
64.1 \\
70.5\end{array}$ & \multicolumn{2}{|c|}{$\begin{array}{l}58.1 \\
69.7 \\
76.7\end{array}$} \\
\hline Enorgy Demand, $k W \mathrm{hr}$ & 4216 & 130 & 1 & 34 & \multicolumn{2}{|c|}{95} \\
\hline
\end{tabular}

Figure 11. RTG Voltage Profile

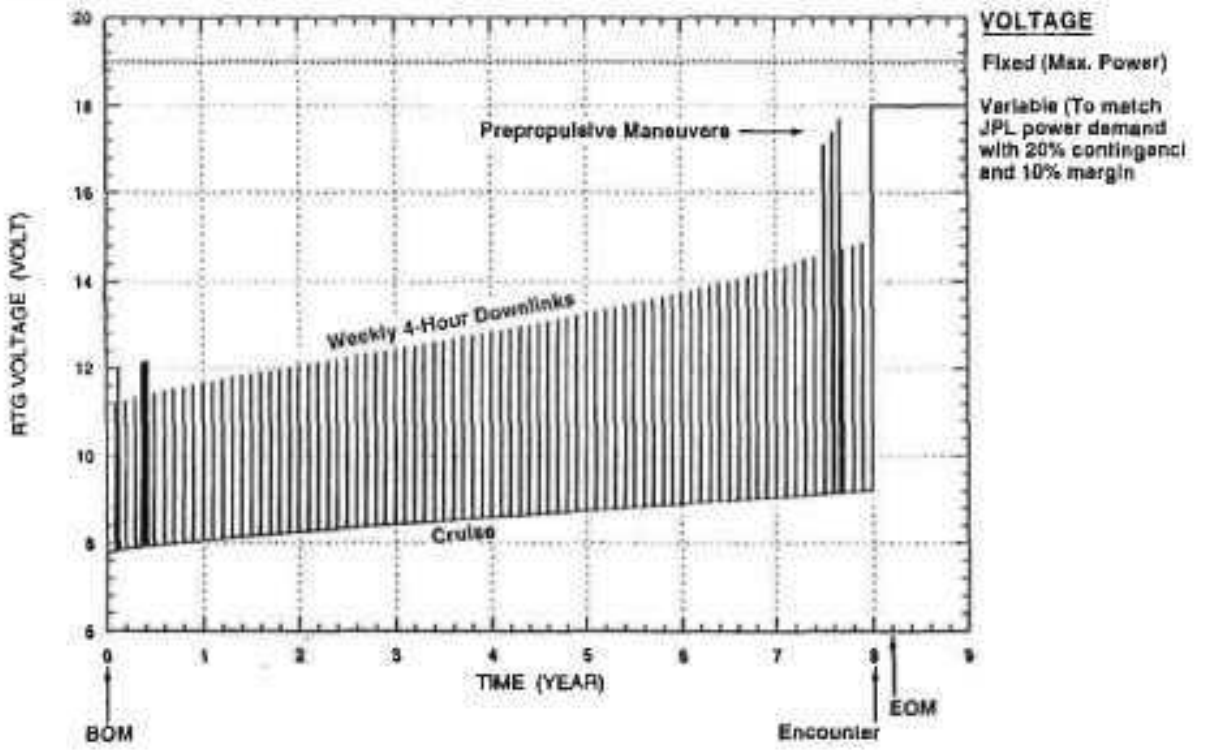


It should be noted that the author makes no claim whether the postulated voltage variation is a feasible or practical option. Clearly, its acceptability will have to be assessed by the user agency, NASA and JPL.

Figure 12 shows the resultant variation in hot-junction temperature. As can be seen, the variable-voltage RTG is running 50 to $60^{\circ} \mathrm{C}$ cooler than the fixedvoltage RTG during most of the cruise. The consequent effect on thermoelectric degradation is displayed in Figure 13. As can be seen, the variable-voltage scherne can reduce the thermoelectric degradation during the mission from $8.3 \%$ to $4.7 \%$.

Finally, Figure 14 compares the RTG's power output for the two voltage schemes. For the variable-voltage scheme, the RTG's output always matches JPL's stipulated margin goal before encounter, and exceeds it thereafter. Thus, the variable-voltage scheme - if acceptable - would eliminate the need for the shunt regulator and its radiator, would fully meet the power goal for prepropulsive maneuvers, and would provide a $16 \%$ margin above the EOM power demand plus contingencies.

\section{REFERENCES}

1 Schock, A., and Chuen Tak Or, "Effect of Fuel and Design Options on RTG Performance Versus PFF Power Demand," for presentation at the 29th Intersociety Energy Conversion Engineering Conference, held in Monterey, CA, 7-12 August 1994.

2 Schock, A., "Design, Analysis, and Optimization of RTG for Solar Polar Mission," 14th intersociety Energy Conversion Engineering Conference, held in Boston, MA, 5-10 August 1979.

3 Schock, A., "RTG Options for Pluto Fast Flyby Mission," 44th Congress of the International Astronautical Federation," held in Graz, Austria, 16-22 October 1993.

\section{Figure 12. Hot-Junction Temperature Versus Time}

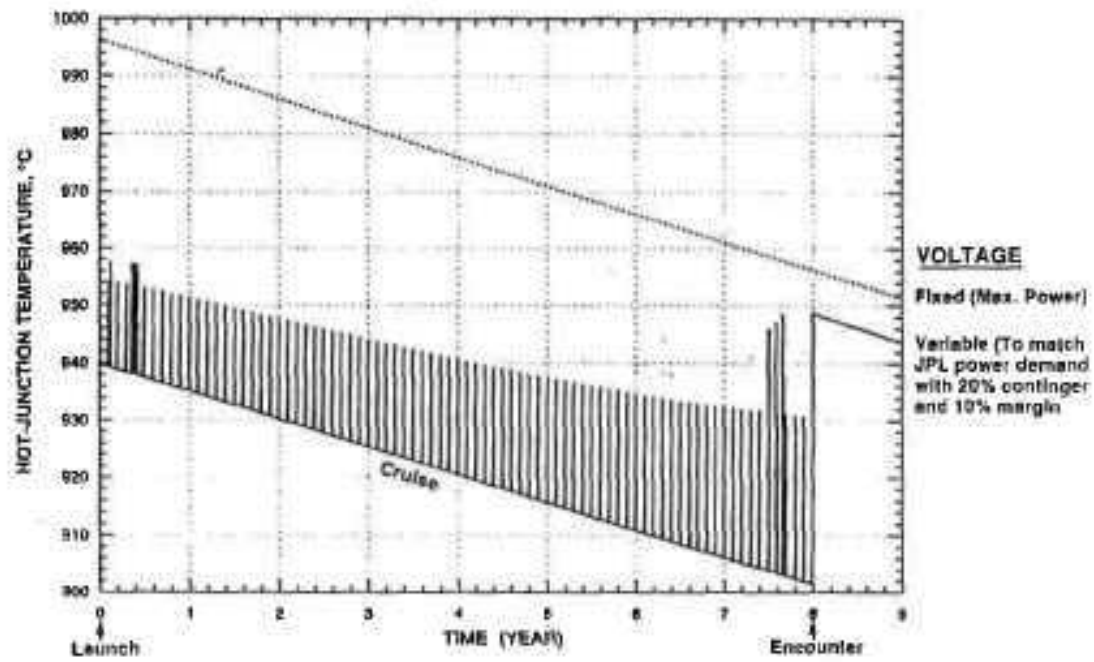

Figure 13. Thermoelectric Degradation

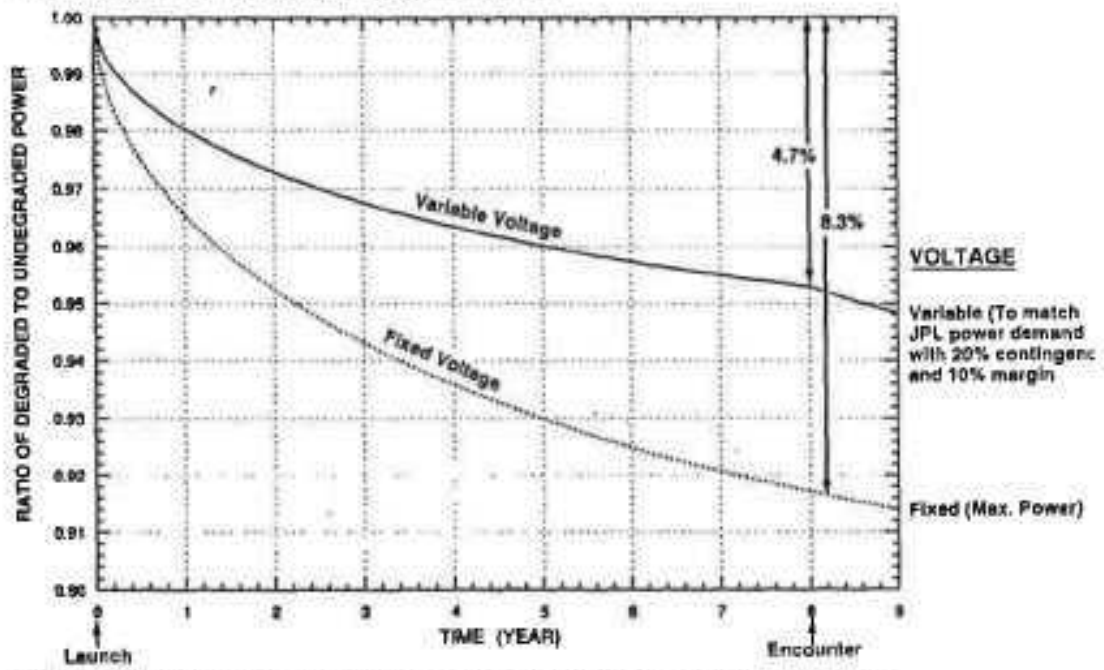

Figure 14. Effect of Variable-Voltage Operation on EOM Margin

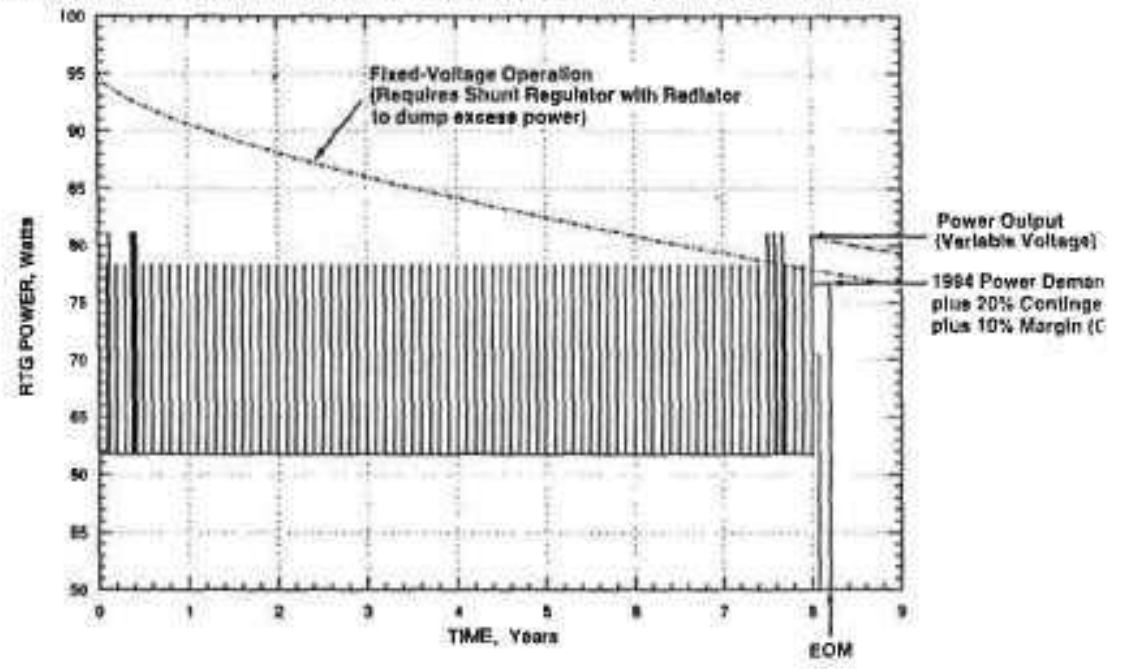

